\title{
Hsp90 Inhibitor Geldanamycin Enhances the Antitumor Efficacy of Enediyne Lidamycin in Association with Reduced DNA Damage Repair
}

\author{
Fei-Fei Han ${ }^{\&}$, Liang Li ${ }^{\&}$, Bo-Yang Shang, Rong-Guang Shao, Yong-Su Zhen*
}

\begin{abstract}
Inhibition of heat shock protein 90 (Hsp90) leads to inappropriate processing of proteins involved in DNA damage repair pathways after DNA damage and may enhance tumor cell radio- and chemo-therapy sensitivity. To investigate the potentiation of antitumor efficacy of lidamycin (LDM), an enediyne agent by the Hsp90 inhibitorgeldanamycin (GDM), and possible mechanisms, we have determined effects on ovarian cancer SKOV3, hepatoma Bel-7402 and HepG2 cells by MTT assay, apoptosis assay, and cell cycle analysis. DNA damage was investigated with $\mathrm{H} 2 \mathrm{AX} \mathrm{C}$-terminal phosphorylation $(\gamma \mathrm{H} 2 \mathrm{AX})$ assays. We found that GDM synergistically sensitized SKOV-3 and Bel-7402 cells to the enediyne LDM, and this was accompanied by increased apoptosis. GDM pretreatment resulted in a greater LDM-induced DNA damage and reduced DNA repair as compared with LDM alone. However, in HepG2 cells GDM did not show significant sensitizing effects both in MTT assay and in DNA damage repair. Abrogation of LDM-induced $G_{2} / M$ arrest by GDM was found in SKOV-3 but not in HepG2 cells. Furthermore, the expression of ATM, related to DNA damage repair responses, was also decreased by GDM in SKOV-3 and Bel-7402 cells but not in HepG2 cells. These results demonstrate that Hsp90 inhibitors may potentiate the antitumor efficacy of LDM, possibly by reducing the repair of LDM-induced DNA damage.
\end{abstract}

Keywords: Geldanamycin - DNA damage repair - lidamycin - enediyne - ATRIP

Asian Pac J Cancer Prev, 15 (17), 7043-7048

\section{Introduction}

DNA repair enables tumor cells to survive from DNA damage induced by chemotherapeutic treatments or ionizing radiation (IR), and DNA repair proteins have become key targets for therapy in combination with radiation and or chemotherapeutic agents as a means of enhancing cell killing (Burdak-Rothkamm and Prise, 2009). Therefore, inhibitors of specific DNA repair pathways might prove efficacious when used in combination with DNA-damaging chemotherapeutic drugs or IR (Arlander et al., 2003; Quanz et al., 2009).

Lidamycin (LDM, also called C-1027) is an enediyne antitumor antibiotic produced by Streptomyces globisporus C-1027. It is currently being evaluated in phase II clinical trials as a potential chemotherapeutic agent in China (Shao and Zhen, 2008; Liu et al., 2009). LDM potently induces DNA damage with a high ratio of double strand breaks (DSBs) to single strand breaks (Xu et al., 1994; Shao and Zhen, 2008), leading to potent cytotoxicity in vitro and marked inhibition of tumor growth in vivo (Zhen et al., 1997; Huang et al., 2005; Chen et al., 2007). Repair of LDM-induced DNA damage is dependent on both ATM and ATR, and LDM cytotoxicity is elevated in cells deficient in both ATM and ATR (Dziegielewski and Beerman, 2002; Kennedy and Beerman, 2006). Hence, inhibiting DNA repair responses following LDM-induced damage could potentially increase the cytotoxicity and antitumor efficacy of LDM.

Hsp90 is important for stabilization and trafficking of tyrosine and serine/threonine kinases that are activated in response to genotoxic stress, including those that are essential for survival of cancer cells (Koll et al., 2008). Some Hsp90 inhibitors are currently in phase I/II clinical trials in combination with IR or chemotherapeutic agents (Dote et al., 2006). Several reports show that Hsp90 inhibitors enhance the effect of DNA damaging agents (Kobayashi et al., 2005; Solar et al., 2007; McCollum et al., 2008; Moran et al., 2008; Sawai et al., 2008), and some studies indicate that Hsp90 inhibitors decrease DNA damage repair by inhibiting ATM-dependent repair mechanisms (Dote et al., 2006; Koll et al., 2008).

To explore if Hsp90 inhibitors could decrease DNA damage response induced by LDM (which is dependent on both ATM and ATR), we tested the effects of geldanamycin (GDM) on LDM-induced DSBs and apoptosis in human ovarian cancer SKOV-3 cells, hepatoma cancer Bel-7402 cells and HepG2 cells. Our results suggest that GDM 
pretreatment potentiated the cytotoxicity of LDM and decreased repair of LDM-induced DNA damage in SKOV3 and Bel7402 cells. To our knowledge, this is the first report that Hsp90 inhibition can sensitize tumor cells to LDM by decreasing DNA damage repair.

\section{Materials and Methods}

\section{Cell culture}

SKOV-3 cells, Bel-7402, and HepG2 cells were maintained in monolayer culture in DMEM medium with $10 \%$ fetal bovine serum in a humidified atmosphere of $5 \% \mathrm{CO}_{2}$.

\section{Chemicals and reagents}

LDM (provided by Professor Lian-fang Jin of our institute) was prepared at $10 \mu \mathrm{M}$ in $0.9 \% \mathrm{NaCl}$ solution and stored at $-80^{\circ} \mathrm{C}$ until use. GDM was purchased from Sigma and reconstituted according to the manufacturer's instructions. All other analytical grade chemicals were purchased from Sigma. Antibodies respectively against ATM, phospho-ATM, ATR, phospho-Chk1, phosphoChk2,ATR interaction protein (ATRIP), and $\gamma \mathrm{H} 2 \mathrm{AX}$ were purchased from Cell Signaling. Anti-actin antibody was from Santa Cruz.

\section{Cell proliferation assay}

Cells were seeded at 4000 cells/well in 96-well tissue culture plates (Costar, Cambridge, Massachusetts, USA). After overnight incubation, triplicate wells were treated with varying concentrations of LDM for $48 \mathrm{~h}$ with or without $16 \mathrm{~h}$ pretreatment with $100 \mathrm{nM}$ GDM. Then, 20 $\mu$ MTT solutions $(5 \mathrm{mg} / \mathrm{ml}$ in PBS) were added to each well and incubated for $4 \mathrm{~h}$ at $37^{\circ} \mathrm{C}$. The MTT formazan was dissolved in $150 \mu \mathrm{l}$ DMSO and absorbance at a wavelength of $570 \mathrm{~nm}$ was measured by a Multiskan MK3 microplate reader (Thermo Labsystem, USA).

\section{Immunofluorescence}

Cells were exposed to LDM for various periods of time following a $16 \mathrm{~h}$ pretreatment with GDM. Cells grown on tissue culture slides were fixed with $4 \%$ paraformaldehyde, permeabilized with $0.2 \% \mathrm{NP} 40$, and blocked with $1 \%$ bovine serum albumin (BSA) in PBS. The slides were incubated with primary antibodies overnight at $4^{\circ} \mathrm{C}$ and with secondary antibodies (DyLight goat anti-rabbit IgG; 1:500) and Hoechst in PBS with 1\% BSA. The primary antibody used for immunostaining was phospho-H2AX (Cell Signaling, USA) at 1:200.

\section{Cell cycle analysis}

After 16h GDM pretreatment, cells were exposed to LDM. Then cells were fixed in ice-cold $70 \%$ ethanol and stored at $-20^{\circ} \mathrm{C}$ for $24 \mathrm{~h}$ before analysis. For cell cycle analysis, cells were washed twice in PBS and stained with $50 \mathrm{mg} / \mathrm{ml}$ propidium iodide and $200 \mathrm{mg} / \mathrm{ml}$ RNase A for $30 \mathrm{~min}$. The samples were analyzed on a fluorescenceactivated cell sorter.

\section{Apoptosis assay by annexin V-FITC staining}

To quantify apoptosis, cells were stained with annexin V and PI using an Annexin V-FITC apoptosis kit (Biovision Inc., CA, USA) following the protocol provided by the manufacturer. Briefly, cells were harvested by trypsinization and washed once with cold PBS. Cell pellets were resuspended in $500 \mu \mathrm{l}$ binding buffer. Then, $5 \mu \mathrm{l}$ of annexin V-FITC and $10 \mu \mathrm{l}$ PI working solution were added into $500 \mu \mathrm{l}$ of cell suspension. The cells were incubated at room temperature for $10 \mathrm{~min}$ in the dark, and then analyzed for apoptosis by flow cytometry.

\section{Immunoblot analysis}

Cells were exposed to LDM for $24 \mathrm{~h}$ after $16 \mathrm{~h}$ pretreatment of GDM. Cell culture monolayers were washed twice with ice-cold PBS and lysed with the lysis buffer containing $50 \mathrm{mM}$ Tris- $\mathrm{HCl}(\mathrm{pH} 7.5), 150 \mathrm{mM}$ $\mathrm{NaCl}, 2 \mathrm{mM}$ EDTA, 2mM EGTA, 1 mM dithiothreitol, $1 \%$ Nonidet $P-40,0.1 \%$ SDS, protease inhibitors (1 $\mathrm{mM}$ PMSF, $10 \mathrm{mg} / \mathrm{ml}$ aprotinin, $10 \mathrm{mM}$ leupeptin and $10 \mathrm{mM}$ pepstatin) and phosphatase inhibitors $(20 \mathrm{mM}$ $\beta$-glycerophosphate, $50 \mathrm{mM} \mathrm{NaF}$ and $1 \mathrm{mM} \mathrm{Na3VO} 4)$. Protein concentration was determined by the BCA protein assay (Pierce Chemical Co., Rockford, Illinois, USA). Equal amounts of protein samples were separated by SDSPAGE and transferred to PVDF membranes (Millipore, Bedford, Massachusetts, USA) which were then incubated in blocking solution ( $5 \%$ bovine serum albumin in $20 \mathrm{mM}$ Tris- $\mathrm{HCl}, 150 \mathrm{mM} \mathrm{NaCl}, 0.1 \%$ Tween-20) (TBS-T), followed by incubation with the indicated antibodies at $4^{\circ} \mathrm{C}$ overnight. Membranes were then washed in TBS-T and incubated with horseradish peroxidase-conjugated secondary antibodies for $1 \mathrm{~h}$ at room temperature. The antibody detection was performed by the enhanced chemiluminescence technique (Millpore).

\section{Results}

GDM sensitizes SKOV-3 cells and Bel-7402 cells to LDM

MTT results showed that LDM markedly inhibited cell growth in a dose dependent manner. At the concentration of 100nM, GDM showed moderate inhibition of cell proliferation. Therefore, in subsequent experiments, 100 $\mathrm{nM}$ of GDM was chosen as an appropriate concentration for combination with varying concentrations of LDM to determine the augmentation effects on the three cell types under study.

After pre-treatment with GDM for 16h, the cells were exposed to different concentrations of LDM for $48 \mathrm{~h}$. As shown in Figure 1, LDM induced growth inhibition was enhanced in GDM-pretreated SKOV3 cells (Figure 1A, B) and Bel-7402 cells (Figure 1C,D). The potentiation of LDM cytotoxicity by GDM Hsp90 inhibition was more marked in Bel-7402 cells than in HepG2 cells (Figure 1E, F).

Table 1 showed the $\mathrm{IC}_{50}$ values of LDM at different GDM doses in the three cell lines. GDM pretreatment decreased the $\mathrm{IC}_{50}$ value of LDM in SKOV-3 (LDM/ LDM+GDM $100 \mathrm{nM}, p=0.0087$; LDM/LDM+GDM 500 $\mathrm{nM}, P=0.0028)$ and Bel-7402 cells (LDM/LDM+GDM $100 \mathrm{nM}, P=0.0150 ; \mathrm{LDM} / \mathrm{LDM}+\mathrm{GDM} 500 \mathrm{nM}$, $P=0.0156$ ), but not in HepG2 cells (LDM/LDM+GDM 100 $\mathrm{nM}, P=0.1339 ;$ LDM/LDM+GDM $500 \mathrm{nM}, P=0.6727)$. 
Table 1. Determined IC $_{50}$ Values on Different Cancer Cell Lines

\begin{tabular}{|c|c|c|c|}
\hline \multirow[t]{2}{*}{ Groups } & \multicolumn{2}{|l|}{$\mathrm{IC}_{50}(\mathrm{nM})$} & \multirow[b]{2}{*}{ LDM+500 nM GDM } \\
\hline & LDM & LDM+100 nM GDM & \\
\hline SKOV-3 & $0.363 \pm 0.041$ & $0.056 \pm 0.009$ & $0.0543 \pm 0.013$ \\
\hline Bel-7402 & $0.19 \pm 0.044$ & $0.05 \pm 0.02$ & $0.0167 \pm 0.0057$ \\
\hline HepG2 & $0.143 \pm 0.051$ & $0.086 \pm 0.011$ & $0.121 \pm 0.034$ \\
\hline
\end{tabular}

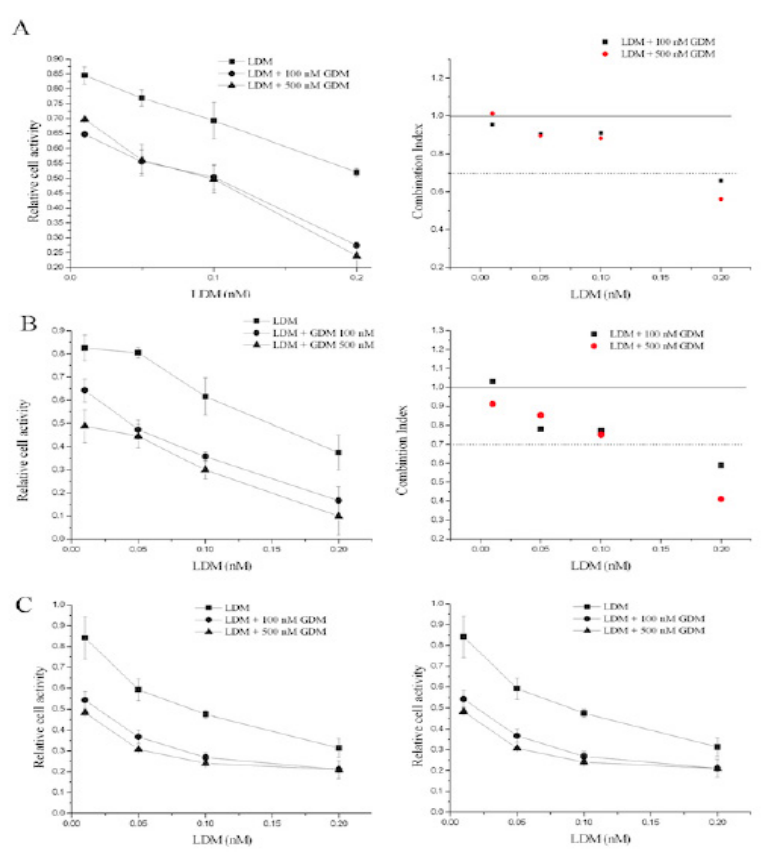

Figure 1. Effect of GDM on LDM-Induced Cytotoxicity in SKOV-3 and Bel-7402 Cells. Shown is the cytotoxicity of the GDM-LDM combination relative to the effect of the two agents alone using the combination index $(\mathrm{Cl})$, which determines whether the cytotoxicity for the combination is greater than $(\mathrm{CI}<1)$, equal to $(\mathrm{CI}=1)$, or less than $(\mathrm{Cl}>1)$ the additive effect of the individual agents (McCollum et al., 2008). Cells were exposed to GDM at $100 \mathrm{nM} \mathrm{GDM}$ (circle) and $500 \mathrm{nM}$ (triangle) separately for $16 \mathrm{~h}$, and then to various concentrations of LDM for $48 \mathrm{~h}$ or exposed to LDM alone for $48 \mathrm{~h}$. Cell viability was determined by MTT assay. A) SKOV-3 cell viability curves, bars, SE, and combination index values for SKOV-3 cell. B) Bel-7402 cell viability curves, and combination index values for Bel-7402 cells. C) Effect of GDM on LDM-induced cytotoxicity in HepG2 cells

\section{GDM potentiates LDM-induced apoptosis}

The augmentation of LDM-induced apoptosis by Hsp90 inhibitor was examined with annexin V-PI staining assay. Consistent with above results from MTT assay, LDM induced much higher apoptotic rates in GDM pretreated cells than in non-pretreated cells. Bel7402 and HepG2 cells were treated with $0.01 \mathrm{nM}$ LDM with fresh GDM-free medium for $24 \mathrm{~h}$ after exposed to GDM (100 $\mathrm{nM}$ ) for 16 hours, and the annexin $\mathrm{V}$ positive cell were determined. As shown in Figure. 2, cells treated with LDM plus GDM had more percent of annexinVpositive cell than with LDM or GDM alone in Bel7402 cells (Figure 2A). However, in HepG2 cells the percent of annexinV positive cell by GDM did not significantly increase in as Bel-7402 cells (Figure 2B).
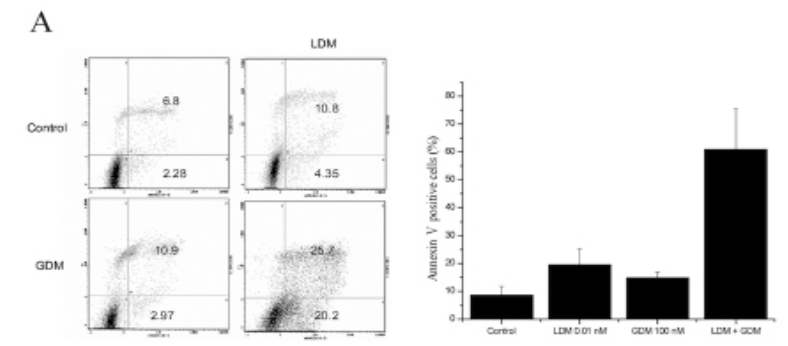

B
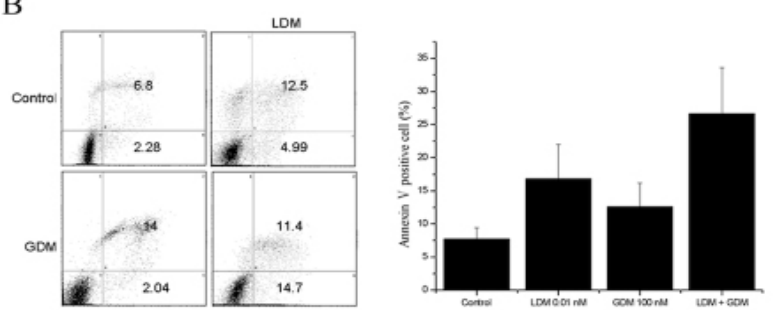

Figure 2. Flow cytometry was Used to Detect the Apoptosis Ratios of Cancer Cells Exposed to LDM, GDM or the Combination for 16h. Cells were harvested and labeled with a combination of Annexin V-FITC and propidium iodide. A) Analysis apoptosis for Bel7402 cell, columns, mean; bars, SE. B) Analysis apoptosis for HepG2 cell

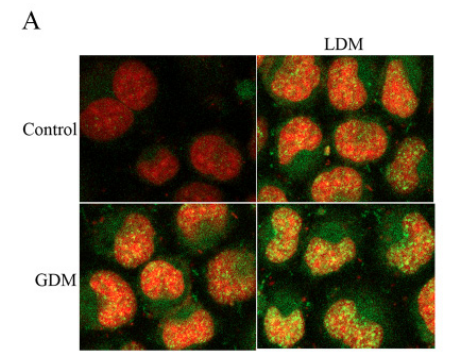

B

Figure 3. LDM-induced DNA damage was enhanced by GDM. A) Bel7402 cells were exposed to GDM (100 nM), fed fresh GDM-free medium with $0.01 \mathrm{nM}$ LDM, and the number $\gamma \mathrm{H} 2 \mathrm{AX}$ foci were observed by confocal microscopy. $\gamma \mathrm{H} 2 \mathrm{AX}$ (green) and nucleus (red) were shown. B) Analysis $\gamma \mathrm{H} 2 \mathrm{AX}$ foci for Bel7402 cell, columns, mean; bars, SE. $\# p=0.002757, *$ $p=0.002049$, ** $p=0.001114$

\section{Pretreatment with GDM enhance LDM-induced DNA damage}

DNA damages caused by IR, UV or radiomimetic agents result in rapid phosphorylation of the histone H2A family member, H2AX, at Ser139, also known as $\gamma \mathrm{H} 2 \mathrm{AX}$ (Dziegielewski and Beerman, 2002; Ward et al., 2004; Clingen et al., 2008; Yajima et al., 2009). Cells were treated with $0.01 \mathrm{nM} \mathrm{LDM}$ with fresh GDM-free medium for $24 \mathrm{~h}$ after exposed to GDM (100 $\mathrm{nM})$ for $16 \mathrm{~h}$, and the number $\gamma \mathrm{H} 2 \mathrm{AX}$ foci were determined. In Bel7402 cells the exposure to GDM and LDM alone had no great effects on the number of $\gamma \mathrm{H} 2 \mathrm{AX}$ foci. For cells exposed to the combination of GDM and LDM, there was great difference in the level of $\gamma \mathrm{H} 2 \mathrm{AX}$ foci compared with GDM or LDM alone (Figure 3A, 3B), suggesting that Hsp90 inhibition enhance the DNA damage effect of LDM.

Pretreatment with GDM impairs LDM-induced DNA repair in SKOV-3 and Bel7402 cells

Cells were exposed to GDM (100 nM) for $16 \mathrm{~h}$, then 
Fei-Fei Han et al

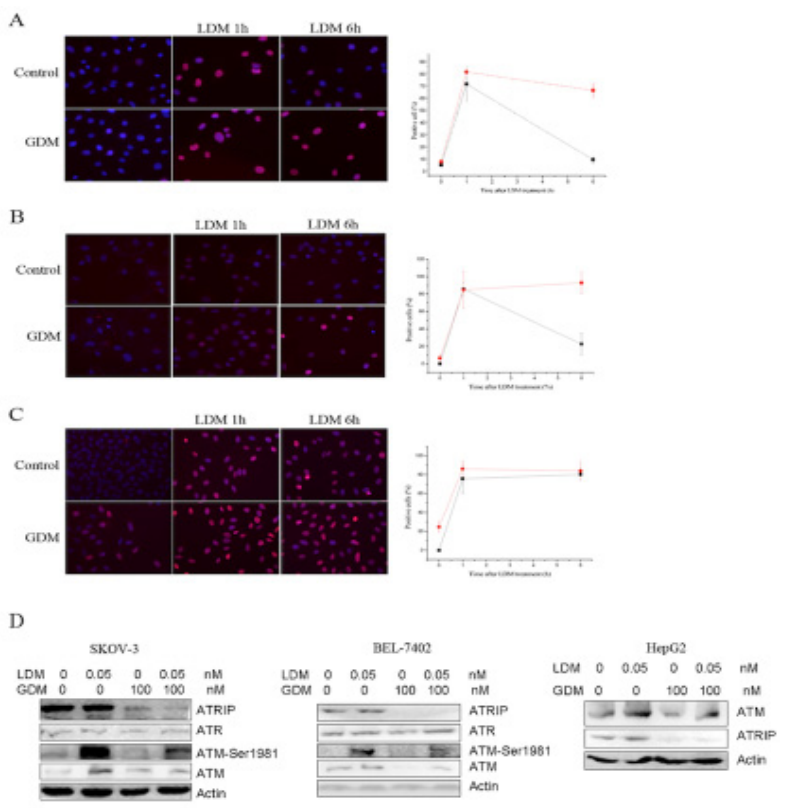

Figure 4. LDM-induced DNA Damage Repair was Decreased by GDM. Cells were exposed to GDM (100 $\mathrm{nM}$ ) for 16 hours, fed GDM-free medium with $0.01 \mathrm{nM}$ LDM; Immuno-cytologically staining for $\gamma \mathrm{H} 2 \mathrm{AX}$ (red) and nucleus (blue) were shown. A) SKOV-3 cells, $\gamma \mathrm{H} 2 \mathrm{AX}$ positive cells were analysis. Shown are results in cells treated with $0.01 \mathrm{nM}$ LDM (square) and $0.01 \mathrm{nM}$ LDM plus $100 \mathrm{nM} \mathrm{GDM} \mathrm{(circle).}$ Bars, SE. The differences between the LDM and the LDM/GDM values were significant at 6 hours $(p<0.05, \mathrm{LDM}$ versus LDM/ GDM). B) Bel7402 cells, $\gamma \mathrm{H} 2 \mathrm{AX}$ positive cells were analysis. Shown are results in cells treated with $0.01 \mathrm{nM}$ LDM (square) and $0.01 \mathrm{nM} \mathrm{LDM}$ plus $100 \mathrm{nM} \mathrm{GDM} \mathrm{(circle).} \mathrm{The} \mathrm{differences}$ between the LDM and the LDM/GDM values were significant at 6 hours $(\mathrm{P}<0.05, \mathrm{LDM}$ versus $\mathrm{LDM} / \mathrm{GDM}), \mathrm{C}) \mathrm{HepG} 2$ cells, $\gamma \mathrm{H} 2 \mathrm{AX}$ positive cells were analysis. Shown are results in cells treated with $0.01 \mathrm{nM}$ LDM (square) and $0.01 \mathrm{nM}$ LDM plus $100 \mathrm{nM}$ GDM (circle). The differences between the LDM and the LDM/GDM values were no significant at 6 hours $(p>0.05$, LDM versus LDM/GDM). D) Effects of GDM and LDM on proteins relating to DNA damage repair. The protein levels were measured by Western blot

changed fresh GDM-free medium with $0.01 \mathrm{nM}$ LDM, and the number $\gamma \mathrm{H} 2 \mathrm{AX}$ positive cells were determined in SKOV-3, Bel7402 and HepG2 cells. In SKOV-3 and Bel7402 cells, the 16-hour exposure to GDM alone had little effect on the number of $\gamma \mathrm{H} 2 \mathrm{AX}$ positive cells, suggesting that Hsp90 inhibition does not induce DNA damage greatly. The $0.01 \mathrm{nM}$ LDM alone induced an increase in the number of $\gamma \mathrm{H} 2 \mathrm{AX}$ positive cell at $1 \mathrm{~h}$, which was reduced by $6 \mathrm{~h}$. For cells exposed to the combination of GDM and LDM, there was no difference in the level of $\gamma \mathrm{H} 2 \mathrm{AX}$ compared with radiation only at the 1-hour time point, suggesting that Hsp90 inhibition does not influence the initial level of DSB induction. However, at the $6 \mathrm{~h}$, the number of $\gamma \mathrm{H} 2 \mathrm{AX}$ positive cell in cultures receiving the combined GDM/LDM treatment was significantly greater compared with the radiation only group. As shown in Figure 4A, 4B, neither LDM nor GDM alone increased $\gamma \mathrm{H} 2 \mathrm{AX}$ positive cells number. The combination of GDM and LDM markedly enhanced $\gamma \mathrm{H} 2 \mathrm{AX}$ positive cells number both in SKOV-3 and Bel-7402 cells.

However, in HepG2 cells the circumstance was

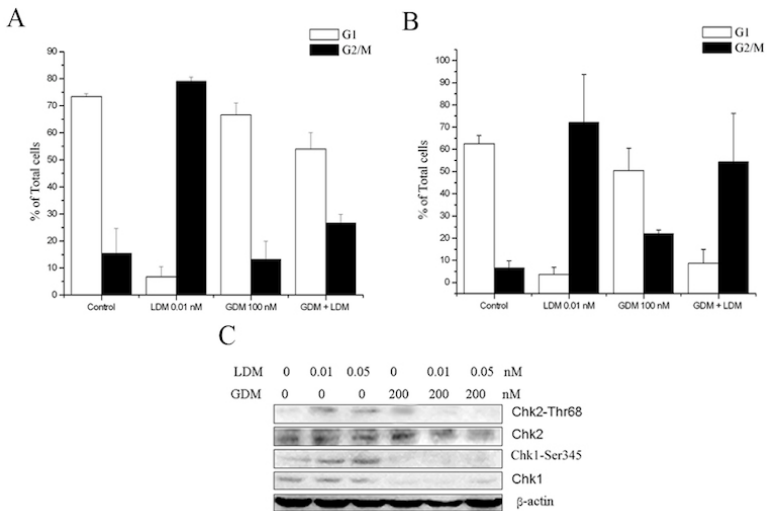

Figure 5. LDM-induced $G_{2} / M$ arrest was abrogated by GDM. A) Cells were exposed to GDM for 16h, and then LDM for further $24 \mathrm{~h}$. Cell cycle distributions were determined by flow cytometry in SKOV-3 cells, bars, SE. B) Cell cycle distributions were determined by flow cytometry in HepG2 cells, bars, SE, C) The activity of Chk1 and Chk2 was analyzed by Western blot in cells exposed to LDM for $24 \mathrm{~h}$ following $16 \mathrm{~h} \mathrm{GDM}$ pretreatment in SKOV-3 cells

different. The $0.01 \mathrm{nM}$ LDM alone induced an increase in the number of $\gamma \mathrm{H} 2 \mathrm{AX}$ positive cells at $1 \mathrm{~h}$, and did not reduce at $6 \mathrm{~h}$ (Figure $4 \mathrm{C}$ ).

We further investigated the mechanism that GDM interferes with the repair kinetics of LDM-induced DNA damage. Both ATM and ATR pathways play significant roles in the response to LDM-mediated DNA damage. Western blot analysis was used to identify the effect of Hsp90 inhibition on ATM and ATR pathways of DNA damage repair. As shown in Figure 4D, the activity of ATM was decreased in both SKOV-3 and Bel-7402 cells pretreated with GDM, suggesting that GDM interfered with the activation of ATM-mediated DSB repair in response to LDM exposure. ATR and ATRIP are also important response pathways involved in DNA damage repair (Dziegielewski and Beerman, 2002). Figure 4D shows that ATM and ATRIP expression were dramatically decreased after 16h GDM treatment.

GDM abrogates LDM-induced $G_{2} / M$ arrest in SKOV-3 but not in HepG2

Cell cycle progression was evaluated with PI staining and FACS analysis. The number of cells in the $\mathrm{G}_{2} / \mathrm{M}$ phase increased from $15 \%$ (control) to $77 \%$ upon treatment with $0.05 \mathrm{nM}$ LDM in SKOV-3 cells. Treatment with $100 \mathrm{nM}$ GDM alone did not significantly induce $\mathrm{G}_{2} / \mathrm{M}$ phase arrest. However, pretreatment with GDM reduced the number of $\mathrm{G}_{2} / \mathrm{M}$ phase cells from $77 \%$ to $29 \%$ (Figure 5A). In HepG2 cells we did not found this result (Figure 5B).

According to Western blot analysis, the LDM-induced phosphorylation of Chk2 and the total expression of Chk1 were both decreased by GDM pretreatment in SKOV-3 (Figure 5C).

\section{Discussion}

Previous reports have established that Hsp90 inhibitors enhance the cytotoxicity of a variety of chemotherapeutic 
drugs and IR (Pelicano et al., 2006; McCollum et al., 2008; Sawai et al., 2008; Watanabe et al., 2008; Wu et al., 2009). In this study, we have shown that the potent cytotoxicity of LDM was enhanced by Hsp90 inhibitor, GDM. This was accompanied by the abrogation of cell cycle arrest and a significant increase in apoptosis induction. Because the anticancer effect of LDM is mainly dependent on DNA damage and previous studies show that Hsp90 inhibitors decrease DNA damage repair responses (Dote et al., 2006; Koll et al., 2008), we hypothesize that Hsp90 inhibitors may enhance LDM cytotoxicity by decreasing DNA damage repair, resulting in augmentation of DNA damage. The present study confirms that Hsp90 inhibitor GDM enhance the antitumor efficacy of LDM in association of reduced DNA damage repair in cancer cells.

C-terminally-phosphorylated histone $\mathrm{H} 2 \mathrm{AX}(\gamma \mathrm{H} 2 \mathrm{AX})$ plays an important role in the cellular response to DNA damage and is evident following both DSBs and SSBs. We measured $\gamma \mathrm{H} 2 \mathrm{AX}$ as a marker for DNA damage and found that GDM significantly enhanced LDM-induced DNA damage. As shown in Bel7402 and SKOV-3 cells, LDM induced a transient surge and subsequent decline in DNA damage. The delayed dispersal of $\gamma \mathrm{H} 2 \mathrm{AX}$ suggested that GDM inhibited the repair of LDM-induced DNA damage in Bel7402 and SKOV-3 cells. In HepG2 cells the $\gamma \mathrm{H} 2 \mathrm{AX}$ level did not reduce at 6 hours LDM treatment. This suggested that the DNA damage repair did not work in HepG2 cells and the effect of GDM potentiation in HepG2 was not as sensitive as in Bel7402 and SKOV-3 cells.

The cellular response to LDM-induced DNA damage is dependent on ATM and ATR (Dziegielewski and Beerman, 2002; Kennedy and Beerman, 2006; Kennedy et al., 2007). And inhibition of ATM and ATR (Sangster-Guity et al., 2011 ) expression has been demonstrated to increase sensitivity to chemotherapeutic drugs. In this research, we found that GDM decreased the LDM-induced $\mathrm{G}_{2} / \mathrm{M}$ phase arrest in SKOV-3 cells but not in HepG2 cells. In HepG2 cells, the inhibition of ATM did not as strong as in SKOV-3 and Bel7402 cells. The augmented effects of LDM by GDM were more potent in SKOV-3 and Bel7402 cells than that in HepG 2 cells. This suggested that GDM can not inhibit LDM induced DNA damage repair sufficiently. Taken together, these data suggested that GDM could increase the effect of LDM by decreasing the DNA damage repair pathways. Results indicate that the synergistic effect is, at least in part, cell type-dependent and related to the DNA damage response induced by LDM.

In summary, we found that Hsp90 inhibitors could enhance the antitumor efficacy of LDM, an enediyne agent with extremely potent cytotoxicity against cancer cells. The molecular mechanism of the combination of Hsp90 inhibitor and enediyne LDM is highly related cellular DNA damage. There occurs a potentiation of DNAdamage associated with a reduction of DNA damage repair.

Recent years the application of Hsp90 inhibitors were gradually went into the bottleneck, the failure of the clinical trials gradually reveal the defects of these drugs. However, the unique mechanism of Hsp90 inhibitors has been the ideal medicine against cancer or virus. Some researchers concluded that combination of chemotherapy drug and chemo-radiation was a safe and effective regimen in management of cancer, meriting further investigation in randomized clinical trials (Jamshed et al., 2014). LDM in our research was a radiomimetic enediyne anticancer drug and showed great effect in combination with Hsp90 inhibitor which was also a good selection in the drug combination. The combination of Hsp90 inhibitor and enediyne agent might be potentially effective in cancer chemotherapy.

\section{Acknowledgement}

The authors declare that there are no conflicts of interest.

\section{References}

Arlander SJ, Eapen AK, Vroman BT, et al (2003). Hsp90 inhibition depletes Chk1 and sensitizes tumor cells to replication stress. J Biol Chem, 278, 52572-7.

Burdak-Rothkamm S, Prise KM (2009). New molecular targets in radiotherapy: DNA damage signalling and repair in targeted and non-targeted cells. Eur J Pharmacol, 625, 151-5.

Chen J, Ouyang ZG, Zhang SH, et al (2007). Down-regulation of the nuclear factor-kappaB by lidamycin in association with inducing apoptosis in human pancreatic cancer cells and inhibiting xenograft growth. Oncol Rep, 17, 1445-51.

Clingen PH, Wu JY, Miller J, et al (2008). Histone H2AX phosphorylation as a molecular pharmacological marker for DNA interstrand crosslink cancer chemotherapy. Biochem Pharmacol, 76, 19-27.

Dote H, Burgan WE, Camphausen K, et al (2006). Inhibition of hsp90 compromises the DNA damage response to radiation. Cancer Res, 66, 9211-20.

Dziegielewski J, Beerman TA (2002). Cellular responses to the DNA strand-scission enediyne C-1027 can be independent of ATM, ATR, and DNA-PK kinases. J Biol Chem, 277, 20549-54.

Huang YH, Shang BY, Zhen YS (2005). Antitumor efficacy of lidamycin on hepatoma and active moiety of its molecule. World J Gastroenterol, 11, 3980-4.

Jamshed A, Hussain R, Iqbal H (2014). Gemcitabine and Cisplatin followed by chemo-radiation for advanced nasopharyngeal carcinoma. Asian Pac J Cancer Prev, 15, 899-904.

Kennedy DR, Beerman TA (2006). The radiomimetic enediyne C-1027 induces unusual DNA damage responses to doublestrand breaks. Biochemistry, 45, 3747-54.

Kennedy DR, Gawron LS, Ju J, et al (2007). Single chemical modifications of the $\mathrm{C}-1027$ enediyne core, a radiomimetic antitumor drug, affect both drug potency and the role of ataxia-telangiectasia mutated in cellular responses to DNA double-strand breaks. Cancer Res, 67, 773-81.

Kobayashi S, Nantz R, Kitamura T, et al (2005). Combined inhibition of extracellular signal-regulated kinases and HSP90 sensitizes human colon carcinoma cells to ionizing radiation. Oncogene, 24, 3011-9.

Koll TT, Feis SS, Wright MH, et al (2008). HSP90 inhibitor, DMAG, synergizes with radiation of lung cancer cells by interfering with base excision and ATM-mediated DNA repair. Mol Cancer Ther, 7, 1985-92.

Liu H, Li L, Li XQ, et al (2009). Enediyne lidamycin enhances the effect of epidermal growth factor receptor tyrosine kinase inhibitor, gefitinib, in epidermoid carcinoma A431 cells and lung carcinoma H460 cells. Anticancer Drugs, 20, 41-9.

McCollum AK, Lukasiewicz KB, Teneyck CJ, et al (2008). 


\section{Fei-Fei Han et al}

Cisplatin abrogates the geldanamycin-induced heat shock response. Mol Cancer Ther, 7, 3256-64.

Moran DM, Gawlak G, Jayaprakash MS, et al (2008). Geldanamycin promotes premature mitotic entry and micronucleation in irradiated p53/p21 deficient colon carcinoma cells. Oncogene, 27, 5567-77.

Pelicano H, Carew JS, McQueen TJ, et al (2006). Targeting Hsp90 by 17-AAG in leukemia cells: mechanisms for synergistic and antagonistic drug combinations with arsenic trioxide and Ara-C. Leukemia, 20, 610-9.

Quanz M, Berthault N, Roulin C, et al (2009). Small-molecule drugs mimicking DNA damage: a new strategy for sensitizing tumors to radiotherapy. Clin Cancer Res, 15, 1308-16.

Sangster-Guity N, Conrad BH, Papadopoulos N, et al (2011 ). ATR mediates cisplatin resistance in a 153 genotype-specific manner. Oncogene, 30, 2526-33.

Sawai A, Chandarlapaty S, Greulich H, et al (2008). Inhibition of Hsp90 down-regulates mutant epidermal growth factor receptor (EGFR) expression and sensitizes EGFR mutant tumors to paclitaxel. Cancer Res, $\mathbf{6 8}, 589-96$.

Shao RG, Zhen YS (2008). Enediyne anticancer antibiotic lidamycin: chemistry, biology and pharmacology. Anticancer Agents Med Chem, 8, 123-31.

Solar P, Horvath V, Kleban J, et al (2007). Hsp90 inhibitor geldanamycin increases the sensitivity of resistant ovarian adenocarcinoma cell line A2780cis to cisplatin. Neoplasma, 54, 127-30.

Ward IM, Minn K, Chen J (2004). UV-induced ataxiatelangiectasia-mutated and Rad3-related (ATR) activation requires replication stress. J Biol Chem, 279, 9677-80.

Watanabe G, Behrns KE, Kim JS, et al (2008). Heat shock protein 90 inhibition abrogates hepatocellular cancer growth through cdc2-mediated G (2)/M cell cycle arrest and apoptosis. Cancer Chemother Pharmacol, 64, 433-43.

Wu X, Wanders A, Wardega P, et al (2009). Hsp90 is expressed and represents a therapeutic target in human oesophageal cancer using the inhibitor 17-allylamino-17demethoxygeldanamycin. Br J Cancer, 100, 334-43.

Xu YJ, Zhen YS, Goldberg IH (1994). C1027 chromophore, a potent new enediyne antitumor antibiotic, induces sequencespecific double-strand DNA cleavage. Biochemistry, 33, 5947-54.

Yajima H, Lee KJ, Zhang S, et al (2009). DNA double-strand break formation upon UV-induced replication stress activates ATM and DNA-PKcs kinases. J Mol Biol, 385, 800-10.

Zhen H, Xue Y, Zhen Y (1997). Inhibition of angiogenesis by antitumor antibiotic $\mathrm{C} 1027$ and its effect on tumor metastasis. Zhonghua Yi Xue Za Zhi, 77, 657-60. 